Reprod. Nutr. Dévelop., 1988, 28 (1), 159-160.

\title{
Addition d'hydrolysat d'huile de soja dans la ration de mouton. Effet sur la dégradation in sacco de la paille et de la cellulose
}

L. BROUdISCOU, C. J. VAN NEVEL $\left({ }^{*}\right)$, D. I. DEMEYER $(*)$, J. P. JOUANY

Laboratoire de la Digestion des Ruminants

I.N.R.A., Theix, 63122 Ceyrat, France.

(*) Research Center for Nutrition

Animal Husbandry and Meat Technology

State University of Ghent, Proefhoevestraat, 10, $9230 \mathrm{Melle}$, Be/gique.

Summary. The addition of soya oil hydrolysate in the diet of 2 mature sheep lowered in sacco digestibility of pure cellulose, by reducing the number of protozoa in faunated sheep. Bacteria are more involved in the decrease of in sacco digestibility of straw.

L'introduction de plus de $5 \%$ de matières grasses dans le régime d'un mouton provoque une baisse importante de la digestibilité des parois dans le rumen. Selon Devendra et Lewis (1974), les lipides protégeraient les fibres de l'action des microbes par adsorption sur les particules. Ikwuegbu et Sutton (1982) soutiennent que l'apport d'huile intoxique les protozoaires ainsi que certaines souches bactériennes (p. e. cellulolytiques), avec d'autant plus d'effet que l'huile est riche en acides gras polyinsaturés. Par des mesures in situ, nous avons cherché à tester ces deux hypothèses, en séparant l'effet des lipides sur les protozoaires de leur effet sur les bactéries.

Matériel et méthodes. Deux moutons adultes, porteurs d'une canule du rumen, reçoivent, à $9 \mathrm{~h}$ et $21 \mathrm{~h}, 300 \mathrm{~g}$ de foin de Ray-Grass d'ltalie et $300 \mathrm{~g}$ d'un aliment concentré aggloméré (pellicules de soja : $40 \%$; orge : $30 \%$; recoupes : $20 \%$; tourteau de soja : $10 \%$ ). Ils sont soumis à 4 traitements. Après défaunation, ils reçoivent le régime témoin, puis la même ration journalière aspergée de $80 \mathrm{~g}$ d'hydrolysat d'huile de soja (HHS) - acides gras libres : $95 \%$; composition partielle en acides gras : C16:0 $0(11,4 \%) ; C 18: 0(4,3) ; C 18: 1(23,7) ; C 18: 2$ $(51,4) ; C 18: 3(5,8)$. Les animaux sont refaunés et les deux régimes précédents sont répétés. Trois substrats - paille de blé broyée $(3 \mathrm{~g})$, cellulose pure ou aspergée de $7 \%$ de HHS $(2 \mathrm{~g})$ - sont placés dans des sachets de nylon $(150 \times$ $50 \mathrm{~mm}$, maille $50 \mu$ ) et introduits à $8 \mathrm{~h} 30$ dans le rumen. Les sachets sont retirés après $24 \mathrm{~h}$ d'incubation pour la cellulose, après $48 \mathrm{~h}$ pour la paille. Ils sont lavés et séchés à $103^{\circ} \mathrm{C}$ en $24 \mathrm{~h}$. Quatre répétitions sont faites par période, animal et substrat. Le taux de disparition du substrat « cellulose » est corrigé en estimant le degré de contamination du résidu par de la matière d'origine microbienne : la différence entre les teneurs en azote (microKjeldhal) du substrat et du résidu est attribuée à l'apport de matière sèche microbienne contenant $8 \%$ d'azote. Les résultats sont traités par analyse de variance.

Résultats et discussion. Chez les animaux refaunés, l'addition d'HHS au régime a entraîné des baisses significatives de la disparition in sacco des 3 substrats (34\% pour la cellulose pure, $31 \%$ pour la cellulose aspergée d'HHS et $46 \%$ pour la paille, tabl. 1) ainsi qu'une diminution significative de $62 \%$ de la densité de population des protozoaires. Chez les animaux défaunés, l'addition d'HHS s'est accompagnée d'une baisse significative de la disparition in sacco de la paille de $30 \%$ mais a été sans effet sur la disparition des deux substrats « cellulose ". Avec le régime témoin le taux de disparition de la cellulose pure a été 
significativement plus faible chez les animaux défaunés que chez les animaux refaunés.

L'enrobage de la cellulose par les acides gras ne semble pas affecter sa disparition des sachets : tous traitements confondus, les taux de disparition de la cellulose pure ou additionnée d'HHS ont été respectivement de 51,8 et 52,2\% après $24 \mathrm{~h}$.

TABL. 1. - Pourcentage de matière sèche disparu des sachets après incubation et densité de population des protozoaires dans le rumen.

\begin{tabular}{lcccc} 
Régime & $\begin{array}{c}\text { Protozoaires } \\
\text { /ml }\end{array}$ & $\begin{array}{c}\text { Cellulose } \\
\text { pure }\end{array}$ & $\begin{array}{c}\text { Cellulose } \\
\text { HHS }\end{array}$ & Paille \\
\hline Témoin & 0 & $47,8 a$ & $52,9 a b$ & $44,5 a$ \\
+ HHS & 0 & $51,0 a$ & $49,6 a$ & $31,0 b$ \\
Témoin & $1,610^{6} a$ & $65,5 b$ & $63,0 b$ & $46,2 a$ \\
+ HHS & $6,110^{5} b$ & $43,0 a$ & $43,4 a$ & $24,9 c$ \\
\hline RSD & $3,310^{2}$ & 10,9 & 11,2 & 2,5 \\
\hline
\end{tabular}

Sur une même colonne, les valeurs affectées des mêmes lettres sont identiques au seuil $P<0,05$.

II semble que l'action du HHS sur la disparition de la paille in sacco ne s'explique pas par une réduction de la faune dans le rumen. A l'inverse, les différences entre animaux défaunés et refaunés d'une part et la comparaison des régimes avec ou sans HHS chez les animaux défaunés d'autre part, laissent supposer que la diminution de la disparition in sacco du substrat " cellulose pure " après addition d'HHS est en partie due à la baisse du nombre des ciliés. Nos résultats montrent que I'HHS a une action négative sur la digestion microbienne des glucides pariétaux dans le rumen qui se manifeste surtout sur les protozoaires dans le cas de la cellulose pure.

Devendra C., Lewis D., 1974. Malaysian Agric. Research., 3, 163-176.

Ikwuegbu O. A., Sutton J. D., 1982. Brit. J. Nutr., 48, 365-375. 